\title{
Effect of Explosive Reactive Armour Cover Plate on Interaction of ERA and Explosively Formed Projectile
}

\author{
Muhammad F. Rasheed (D), ${ }^{1}$ Cheng Wu $\mathbb{D}^{1},{ }^{1}$ and Ali Raza ${ }^{2}$ \\ ${ }^{1}$ Department of Mechatronics, Beijing Institute of Technology, Beijing 10081, China \\ ${ }^{2}$ Center of Excellence, Sciences \& Applied Technologies (CESAT), Islamabad, Pakistan \\ Correspondence should be addressed to Muhammad F. Rasheed; farrukh@bit.edu.cn
}

Received 20 January 2019; Accepted 16 June 2019; Published 11 July 2019

Academic Editor: Isabelle Sochet

Copyright ( 2019 Muhammad F. Rasheed et al. This is an open access article distributed under the Creative Commons Attribution License, which permits unrestricted use, distribution, and reproduction in any medium, provided the original work is properly cited.

\begin{abstract}
Explosive reactive armour (ERA) is used to protect the armoured vehicles against chemical energy warheads and long-rod penetrators. ERA generally consists of an ERA sandwich and an outer steel cover to protect it from unintended initiation. Explosively formed projectiles (EFPs) are used as antiarmour warheads, and their use in top attack antiarmour weapons is increasing. Interaction of EFP with the ERA sandwich alone has been studied in the past. This paper studies the effect of the cover plate and its thickness on the interaction of the EFP and the ERA sandwich. Numerical simulations and experiments have been used to study the interaction. It has been found that the penetration in the target is reduced as the thickness of the cover plate increases. Moreover, the decrease in penetration is directly proportional to the thickness of the cover plate. Also it has been found that the residual EFP after penetrating the cover plate has sufficient energy to initiate the ERA sandwich. The results of the numerical simulation and the experiments are in close agreement.
\end{abstract}

\section{Introduction}

Explosive reactive armour (ERA) is widely used on modern armoured vehicles to protect them against attack from chemical energy warheads. Originally the ERA was developed to defeat shaped charge warheads [1], which form a long stretching jet which has the capability to penetrate deep in the armoured target. Over a period of time, the ERAs have been improved to become effective against kinetic energy penetrators as well. Explosively formed projectile (EFP) warheads form a high-speed projectile which is being employed in top attack antiarmour weapons frequently. Common examples include the overfly shoot down missiles, loitering munitions, and sensor-fused submunitions. Since the ERAs are widely used to enhance the protection of the armoured vehicles, it is very likely that during the top attack engagement of armoured targets with EFP warhead, the EFP will interact with the ERA. The interaction of EFP and ERA sandwich alone has been studied by various researchers including the authors [2-5].
In most practical scenarios, the ERA sandwich is protected with cover plates or is enclosed in protective metal boxes to protect them from elements, and from unintended initiation due to small calibre bullets, shrapnel, etc., this protection can further deteriorate the effectiveness of the EFP warhead.

This paper undertakes the study of the effect of the cover plate of the ERA sandwich on the penetration efficiency of the EFP. The effect of the cover plate has been studied by using both the numerical simulations using LS-DYNA and experiments. The results show that the penetration of the EFP is reduced in proportion to the thickness of the cover plate. The simulations and the experiments have good agreement, and the simulations can successfully be used to simulate the interaction under various conditions.

\section{EFP, Cover Plate, ERA, and Target Layout}

2.1. Layout. The layout used in this study is shown in Figure 1. The layout consists of an EFP, a standoff distance 

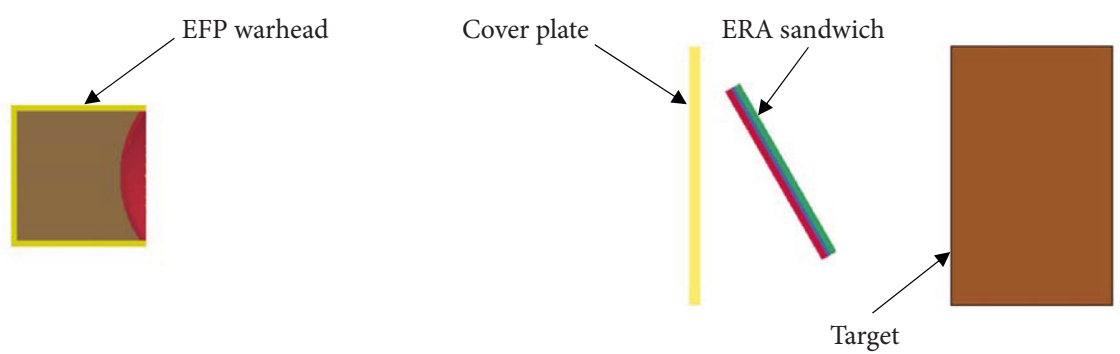

Figure 1: Configuration of EFP warhead, cover plate, ERA, and target used for simulations.

after which there is a cover plate followed by ERA sandwich and the target. The layout has been maintained both for the simulations and the experiments.

2.2. EFP Model. The EFP used for the simulations is a $100 \mathrm{~mm}$ charge diameter EFP which has a charge height of $100 \mathrm{~mm}$, liner is of hemispherical construction with the radius of curvature of $85 \mathrm{~mm}$ and liner thickness $4 \mathrm{~mm}$. The EFP has $5 \mathrm{~mm}$ thick steel casing and is point initiated at the top. Similar EFP has also been used in the study previously carried out by Rasheed et al. [4] to study the interaction of the EFP with ERA. This EFP has been designed based on the relationships presented by Weimann [6] for the effect of various physical parameters of the warhead on the EFP formation.

2.3. Cover Plate, ERA, and Target. The cover plate is an A36 steel plate for which the thickness was varied during the simulations and the experiments to analyse their effect.

The ERA sandwich consists of two A36 plates with C4 explosive sandwiched in between. The ERA plates are $150 \times 150 \times 5 \mathrm{~mm}$ in dimensions, and the C4 explosive is $3 \mathrm{~mm}$ thick. The configuration is referred as 5/3/5 ERA in this study. The inclination angle has been maintained at $30^{\circ}$ throughout this study.

The target plate used is a $125 \mathrm{~mm}$ thick A36 steel plate.

\section{Simulations}

3.1. Simulation Model Setup. The simulation consists of ALE formulation to model the explosive, air, and liner of the EFP, and this enables capturing the large deformations and material flow experienced during the EFP formation. The casing of the EFP has been modelled using the Lagrange formulation to cater for the confinement and breakup effect of the casing. Once the EFP is formed, it flies through the air towards the ERA and the target plate. The covering plate, ERA sandwich, and the target, all have been modelled using Lagrange formulation. The EulerLagrange interaction has been utilized to simulate the penetration and interaction with the Lagrange components. Lagrange formulation has been used to model the penetration problem, as in this formulation, failure and damage can be modelled without complicating the domain.
The 3D domain established for the simulation consists of a half symmetrical model as shown in Figure 2. The half symmetrical model is necessary to simulate the interaction with the inclined explosive reactive armour (ERA) sandwich.

In order to study the effect of the cover plate thickness on the residual penetration in the target plate, the model has been kept constant except varying the thickness of the cover plate. Thickness has been varied in successive simulations from no cover plate to $8 \mathrm{~mm}$ with $2 \mathrm{~mm}$ increment. The standoff between the target and the cover plate has been kept at $425 \mathrm{~mm}$, distance between the cover plate and the ERA is $60 \mathrm{~mm}$, and the distance between the ERA sandwich and the target is $100 \mathrm{~mm}$.

3.2. Material Models. The simulations used the following material and equation of state models to model the complete simulation [7].

3.3. EFP Liner. The Steinberg model has been used for the EFP liner. The Steinberg-Guinan [8] model was developed for high strain rates. In this model, both the shear modulus $G$ and yield strength $\sigma_{y}$ increase with pressure but decrease with temperature. When the temperature reaches the melting point, these quantities also approach zero. The shear modulus and the yield strength are defined by using following equations:

$$
G=G_{0}\left[1+b p V^{1 / 3}-h\left(\frac{E-E_{c}}{3 R^{\prime}}-300\right)\right] e^{-\left(f E /\left(E_{m}-E\right)\right)},
$$

where $G_{0}, b, h$, and $f$ are the input parameters for the material and $E_{c}$ is the cold compression energy and $E_{m}$ is the melt energy:

$$
\sigma_{y}=\sigma_{0}^{\prime}\left[1+b p V^{1 / 3}-h\left(\frac{E-E_{c}}{3 R^{\prime}}-300\right)\right] e^{-\left(f E /\left(E_{m}-E\right)\right)} .
$$

The Gruneisen equation of state has been used for all metallic materials in the simulation model. It defines the pressure for compressed material as

$$
\begin{aligned}
p= & \frac{\rho_{0} C^{2} \mu\left[1+\left(1-\left(\gamma_{0} / 2\right)\right) \mu-(a / 2) \mu^{2}\right]}{\left[1-\left(S_{1}-1\right) \mu-S_{2}\left(\mu^{2} /(\mu+1)\right)-S_{3}\left(\mu^{3} /(\mu+1)^{2}\right)\right]} \\
& +\left(\gamma_{0}+\alpha \mu\right) E,
\end{aligned}
$$




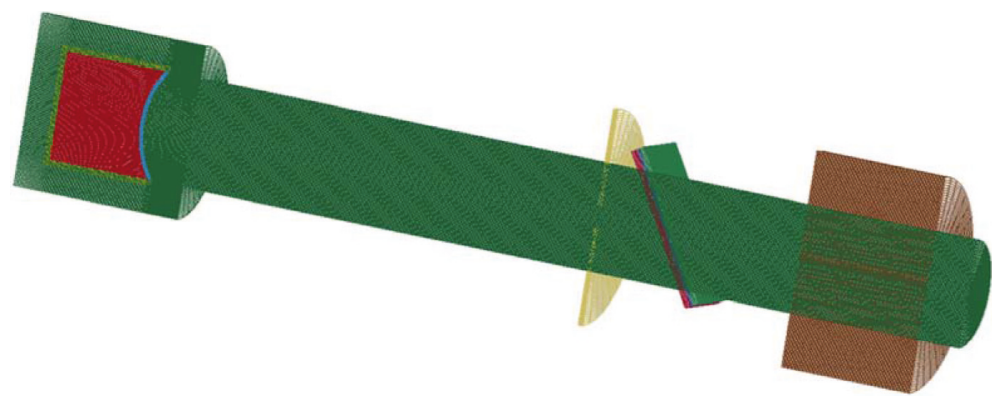

FIgURE 2: Semisymmetric 3D domain including air, EFP, cover plate, ERA, and target.

where $E$ is the internal energy per unit initial volume. $C, S_{1}, S_{2}$, and $S_{3}$ are constants based on the $\mathrm{u}_{\mathrm{s}}-\mathrm{u}_{\mathrm{p}}$ curve. $\gamma_{0}$ is the Gruneisen gamma, and $a$ is the first-order correction to $\gamma_{0}$.

3.4. EFP Main Charge. High explosive burn model and JWL equation of state [9] are used to model the explosive in the EFP warhead. The high explosive burn model is used to determine the lighting time for the explosive element, and the JWL EOS is used to calculate the pressure:

$$
p=A\left(1-\frac{\omega}{R_{1} V}\right) e^{-R_{1} V}+B\left(1-\frac{\omega}{R_{2} V}\right) e^{-R_{2} V}+\frac{\omega E}{V}
$$

where $E$ is the internal energy per unit volume and $V$ is the relative volume and $R_{1}, R_{2}, \omega, A$, and $B$ are the explosive specific constants.

3.5. ERA Explosive. Since the initiation of explosive in the ERA is not ensured, rather it has to be determined based on the shock pressures developed during the interaction of the EFP with the ERA sandwich, the ignition and growth model $[10,11]$ has been used to model the C-4 explosive in the ERA sandwich. In this model, the chemical reaction rate for conversion of unreacted explosive to reaction products consists of three physically realistic terms:

(1) Ignition term in which a small amount of explosive reacts soon after the shock wave compresses it.

(2) Slow growth of reaction as this initial reaction spreads.

(3) Rapid completion of reaction at high pressure and temperature. The form of the reaction rate equation is

$$
\begin{aligned}
\frac{\partial F}{\partial t}= & I(F C R I T-F)^{y}\left(V_{e}^{-1}-1\right)^{3}\left[1+G\left(V_{e}^{-1}-1\right)\right] \\
& +H(1-F)^{y} F^{x} P^{z}\left(V_{p}^{-1}-1\right)^{m},
\end{aligned}
$$

where $F$ is the fraction of explosive that has reacted, $t$ is the time, and remaining are explosive specific values.
3.6. EFP Casing, ERA Cover Plate, ERA Plates, and Target. The Johnson-Cook material model has been used for the EFP casing, cover plate, ERA plates, and target in combination with the Mie-Gruneisen equation of state. The Johnson-Cook model expresses the flow stress as

$$
\sigma_{y}=\left(A+B \bar{\varepsilon}^{p^{n}}\right)\left(1+C \ln \dot{\varepsilon}^{*}\right)\left(1-T^{* m}\right),
$$

where $A, B, C, n$, and $m$ are the material specific constants. $\bar{\varepsilon}^{p}=$ effective plastic strain.

$\dot{\mathcal{\varepsilon}}^{*}=\dot{\bar{\varepsilon}}^{p} / \dot{\mathcal{\varepsilon}}_{0}$ effective plastic strain rate for $\dot{\varepsilon}_{0}=1 \mathrm{~s}^{-1}$.

$$
T^{*}=\frac{T-T_{\text {room }}}{T_{\text {melt }}-T_{\text {room }}} \text {. }
$$

Table 1 lists the values of the material specific constants used in the simulation.

\section{Experimental Setup}

The experiments were carried out to verify the simulation results. The experimental setup is shown in Figure 3. The setup shows the EFP warhead placed on a PVC stand with a plywood plate. The plywood has a $90 \mathrm{~mm}$ diameter hole to enable the EFP to pass through without interacting with the wood. Then after the standoff gap of $500 \mathrm{~mm}$, the cover plate is placed. The distance between the cover plate and the ERA has been maintained at $60 \mathrm{~mm}$. The ERA is at $150 \mathrm{~mm}$ standoff from the target. The whole setup is placed on top of the target plate as shown in Figure 3.

Figure 4 shows the components of the EFP warhead and ERA plate used in the experiments. The ERA plate was constructed using $3 \mathrm{~mm}$ thick $\mathrm{C} 4$ explosive sandwiched between $5 \mathrm{~mm}$ steel plates. The ERA sandwich used was of 5/ $3 / 5$ configuration inclined at $30^{\circ}$ from the horizontal.

For each experiment, the thickness of the cover plate was varied between 2 to $8 \mathrm{~mm}$ and the remaining setup was kept constant. The penetration depth was measured for each test and has been compared with the simulation results.

\section{Results and Discussion}

5.1. Simulations. As described earlier, the simulations have been carried out to study the various aspects of formation and interaction of the EFP with the cover plate, ERA, and residual penetration. This was arranged in a manner to study the contribution of the cover plate in penetration reduction of EFP. Figures 5-8 are the simulation of the EFP interaction with 2 to $8 \mathrm{~mm}$ cover plates at various times. 


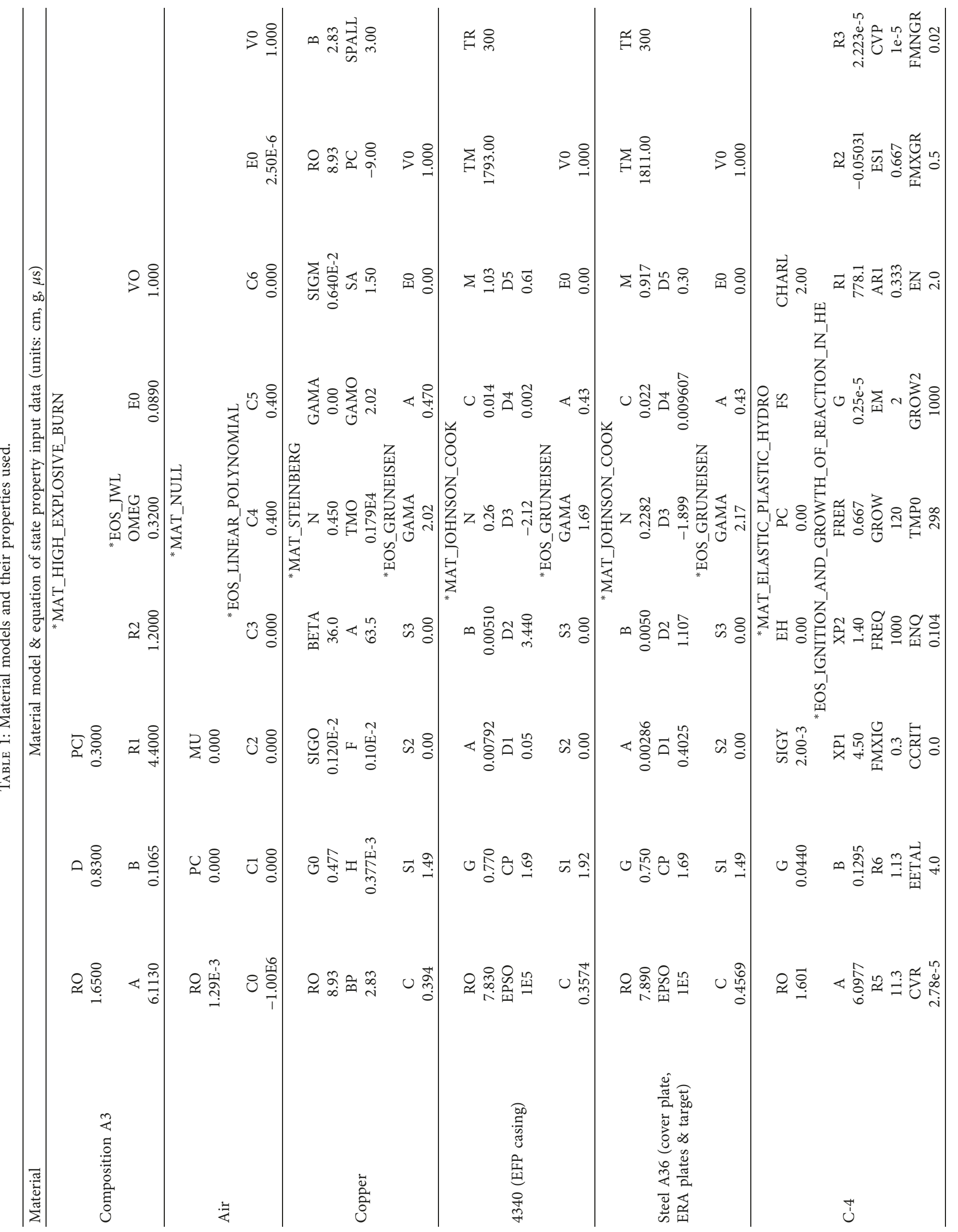




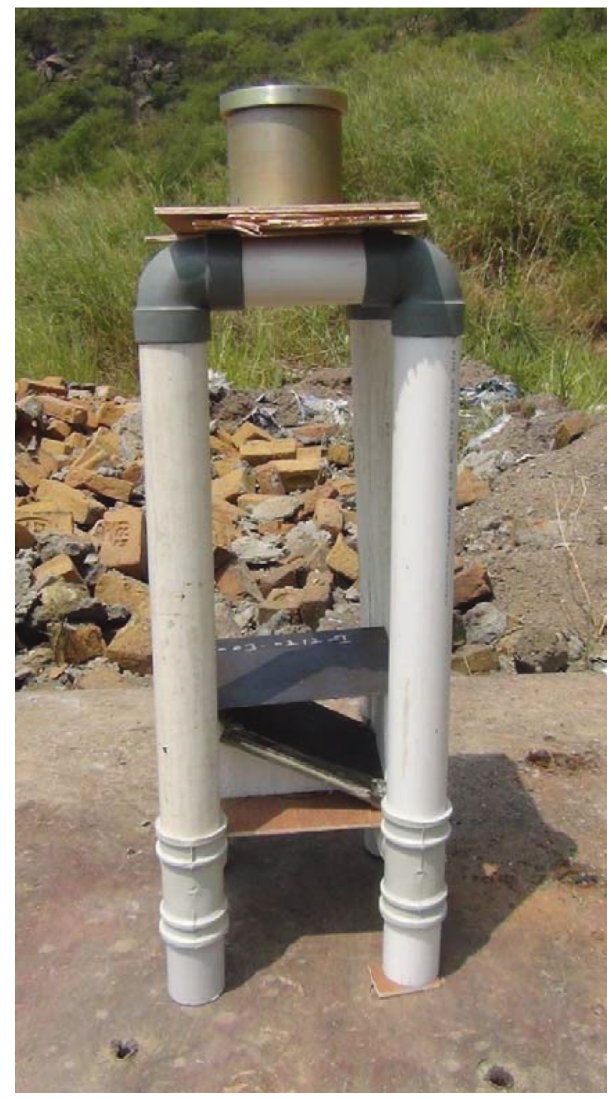

FIGURE 3: Experimental setup showing the EFP warhead on its stand with the ERA and the cover plate.

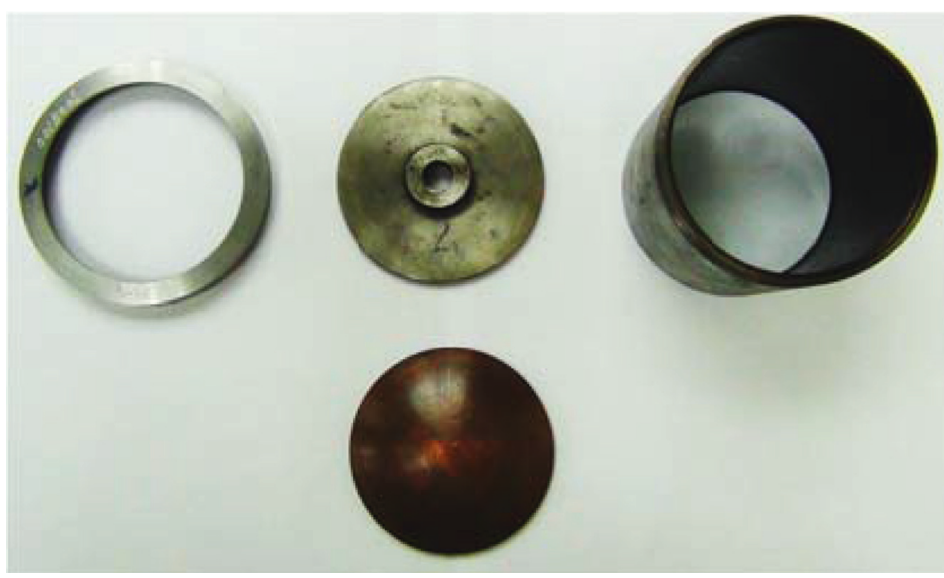

(a)

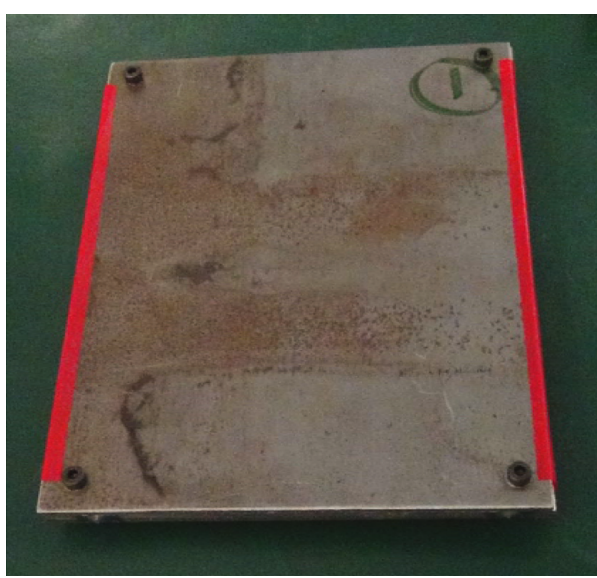

(b)

Figure 4: (a) EFP components and (b) the ERA plates used in the experiments.

From the simulation, it can be concluded that the ERA cover plate does in fact contributes towards the reduction in length of the EFP and it also deteriorates the nose shape of the EFP as well. However the residual EFP has enough energy to initiate the explosive in the ERA. This interaction with the ERA sandwich further reduces the length of the EFP. The residual length of the EFP after interaction with the cover plate and the ERA is shown in Figure 9.
5.2. Experimental Results. The experiments were conducted as described above, and the penetration in the target plate was measured for each experiment. The results show that the penetration depth reduces with the thickness of the cover plate. The resulting penetration holes are shown in Figure 10.

The experiments show a decreasing penetration in the target plate as the thickness of the cover plate increases. 

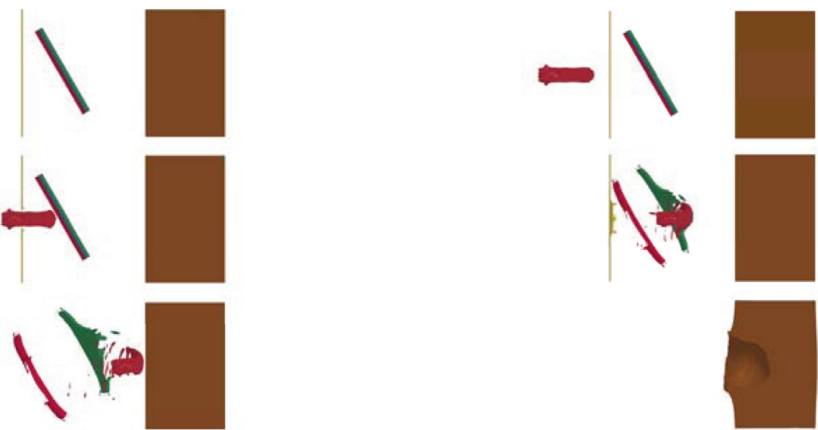

FIGURE 5: Interaction of EFP with ERA having $2 \mathrm{~mm}$ thick cover plate at 0, 190, 230, 281, 316, and $444 \mu \mathrm{s}$.
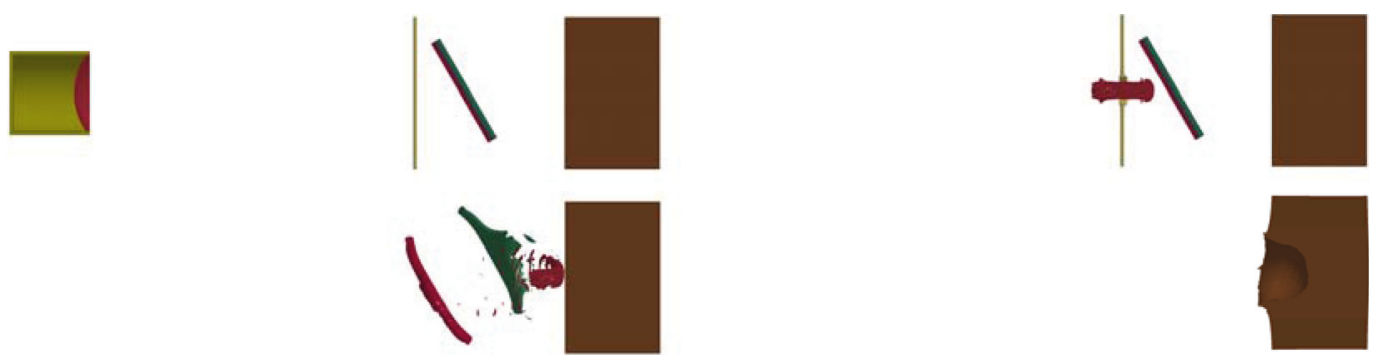

FIGURE 6: Interaction of EFP with ERA having $4 \mathrm{~mm}$ thick cover plate at $0,226,320$, and $450 \mu$ s.
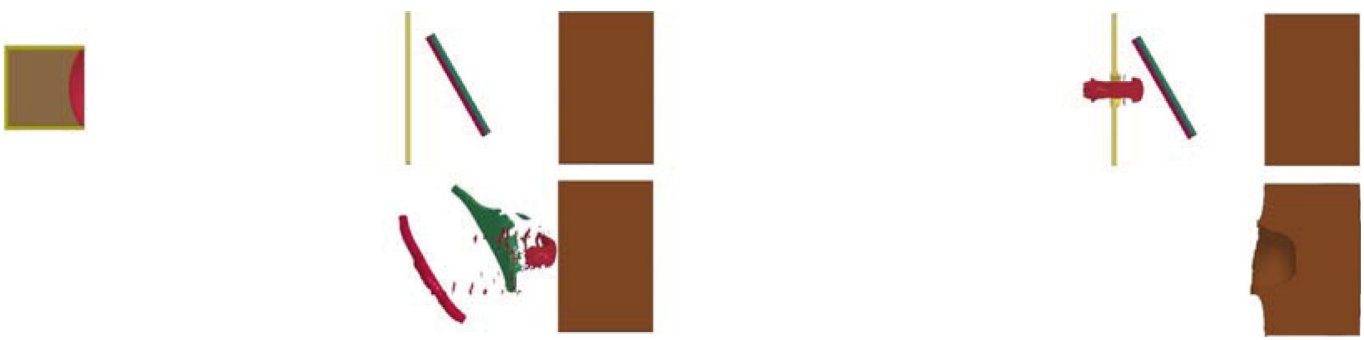

FIGURE 7: Interaction of EFP with ERA having $6 \mathrm{~mm}$ thick cover plate at $0,225,321$, and $405 \mu$ s.
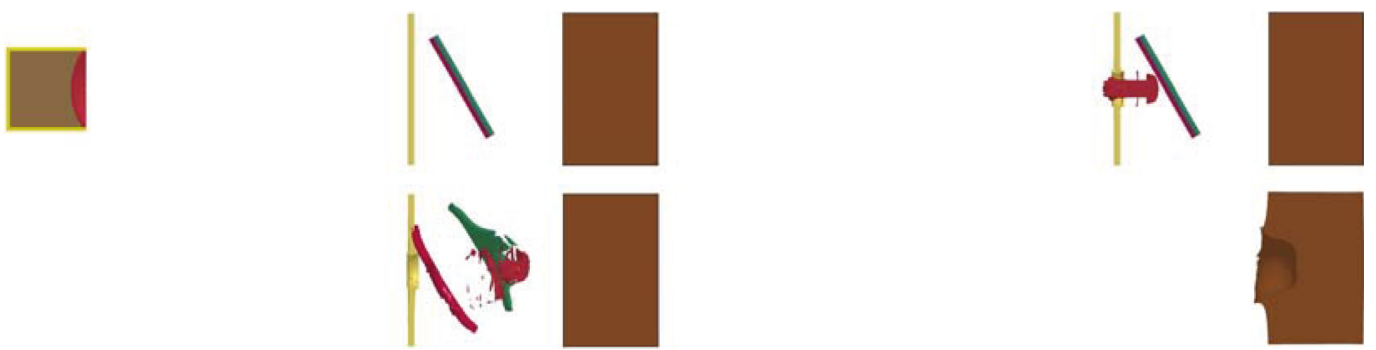

FIGURE 8: Interaction of EFP with ERA having $8 \mathrm{~mm}$ thick cover plate at $0,248,300$, and $481 \mu$ s.

The first test was carried out without any ERA and cover plate to establish a base line as shown in Figure 10(a). The EFP was able to penetrate through the target plate.

Figure 10(b) shows the penetration in the target plate with ERA only and no cover plate. The ERA penetrated $95 \mathrm{~mm}$ in the target. Figure 10(c) shows the penetration in the target plate with $2 \mathrm{~mm}$ cover plate which penetrated $77 \mathrm{~mm}$ deep. Figure $10(\mathrm{~d})$ shows the penetration of $69 \mathrm{~mm}$ with $4 \mathrm{~mm}$ thick cover plate. Figure $10(\mathrm{e})$ is the penetration of $67 \mathrm{~mm}$ when using $6 \mathrm{~mm}$ cover plate, and Figure 10(f) shows the penetration of $57 \mathrm{~mm}$ when $8 \mathrm{~mm}$ cover plate was used. These experiments show that the penetration reduces as the thickness of the cover plate is increased.

5.3. Comparison of Simulations with Experimental Results. As described earlier experiments were carried out to validate the simulation results. The simulations and the experiments 


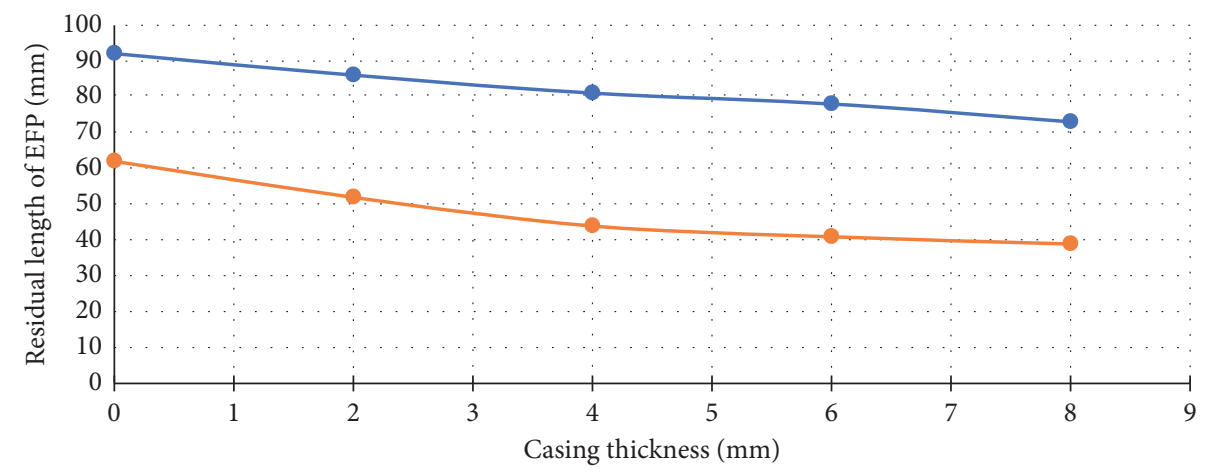

$\rightarrow-$ After cover plate

$\rightarrow$ After ERA

FIgURE 9: Residual length of EFP after interaction with cover plate and ERA.

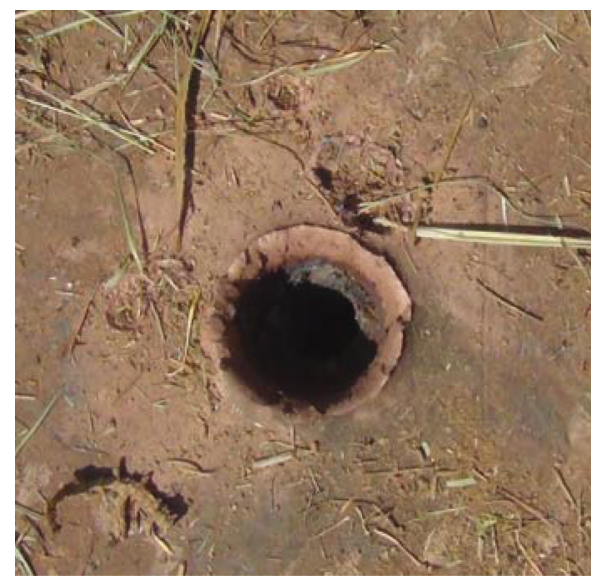

(a)

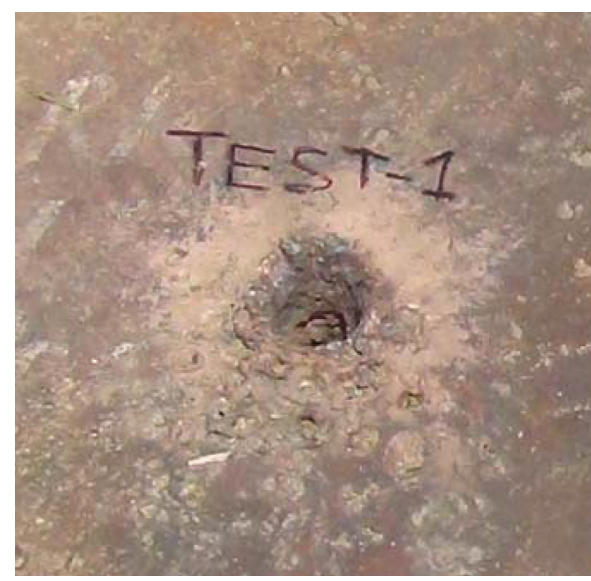

(c)

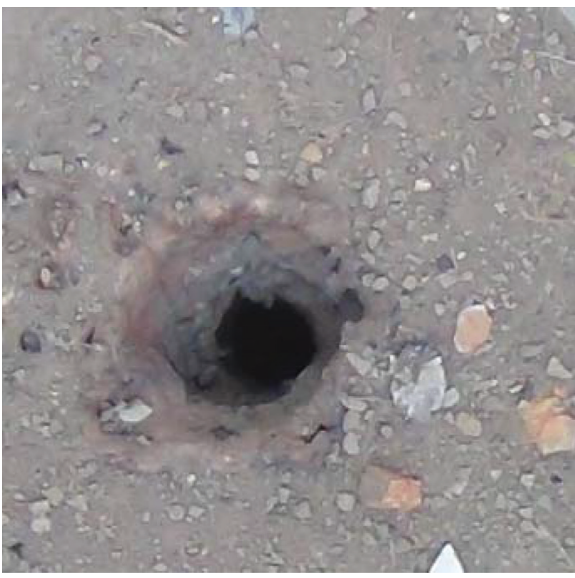

(b)

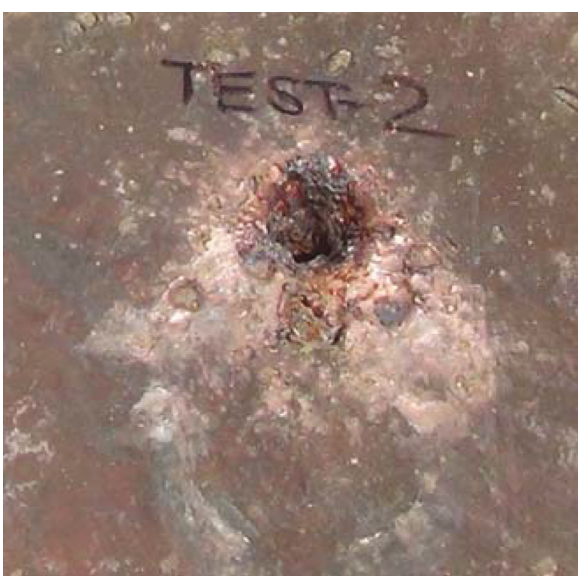

(d)

Figure 10: Continued. 


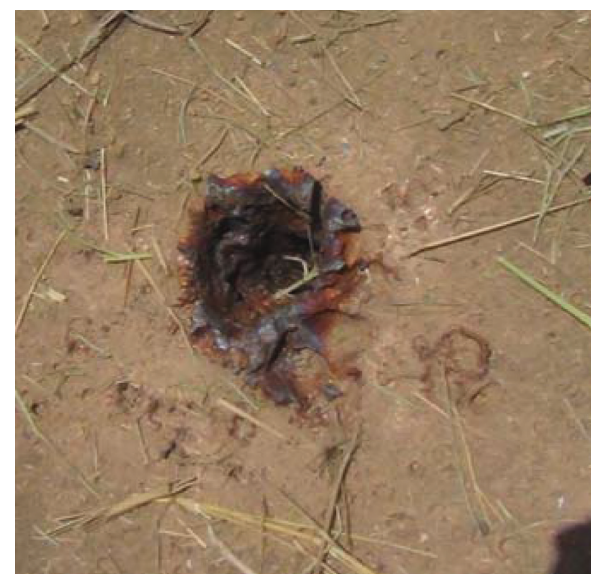

(e)

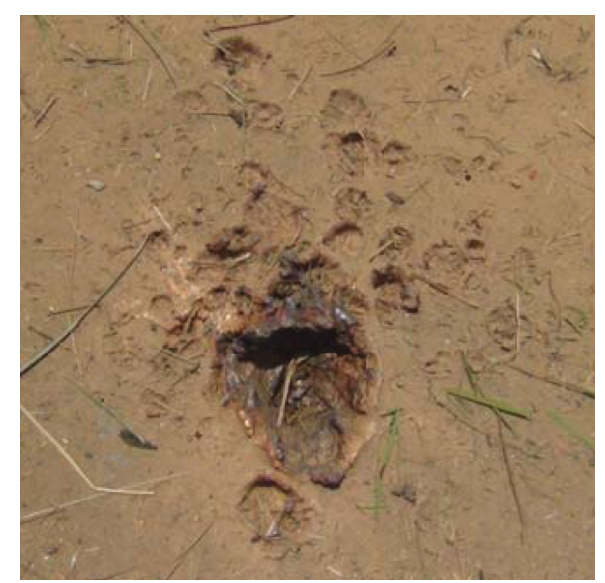

(f)

Figure 10: Penetration in steel target (a) without ERA, (b) without cover plate, (c) $2 \mathrm{~mm}$, (d) $4 \mathrm{~mm}$, (e) $6 \mathrm{~mm}$, and (f) $8 \mathrm{~mm}$ cover plate.

TABLE 2: Comparison of EFP residual penetration after cover and ERA interaction.

\begin{tabular}{lccccc}
\hline Test & $\begin{array}{c}\text { ERA cover } \\
\text { thickness (mm) }\end{array}$ & $\begin{array}{c}\text { Simulated results } \\
\text { Efter cover plate (mm) }\end{array}$ & $\begin{array}{c}\text { EFP residual length } \\
\text { after ERA (mm) }\end{array}$ & Simulated penetration (mm) & Experimental penetration (mm) \\
\hline 1 & No cover plate & 92 & 62 & 87 & 95 \\
2 & 2 & 86 & 52 & 65 & 77 \\
3 & 4 & 81 & 44 & 61 & 69 \\
4 & 6 & 78 & 41 & 56 & 67 \\
5 & 8 & 73 & 39 & & 57 \\
\hline
\end{tabular}

both use the same configuration with $100 \mathrm{~mm}$ charge diameter point initiated EFP, steel cover plate, 5/3/5 ERA at $30^{\circ}$ angle from the target surface, and the steel target. Table 2 and Figure 11 summarize the results of the simulation and the experiments. The results are comparable and show that the penetration reduces as the thickness of the ERA cover plate increases. The decrease is directly proportional to the thickness of the ERA cover plate.

5.4. Effect of Cover Plate with ERA at $45^{\circ}$. As the simulation and experimental study match reasonably well, the study was further extended to analyse the effect of the inclination angle of the ERA plate on the penetration of the EFP, with varying cover plate thickness.

For this set of simulations, the setup was kept the same as in the previous simulations, and only the inclination angle of the ERA sandwich was changed from $30^{\circ}$ to $45^{\circ}$. This has resulted in further reduction in penetration depth, as the increase in inclination angle reduces the residual length of the EFP resulting in reduction in penetration depth. Figures 12 and 13 show the simulation at various time intervals.

The results of simulations with $30^{\circ}$ inclined ERA and $45^{\circ}$ inclined ERA sandwich with 4 and $8 \mathrm{~mm}$ cover plates are given in Table 3, and it shows that the penetration reduces as the inclination angle of the ERA sandwich increases.

\section{Conclusions}

In this paper, the effect of cover plate thickness was studied on the interaction of EFP and ERA using experiments. A numerical model of the EFP warhead, cover plate, ERA sandwich, and target has been established to simulate the experiments conducted and was compared with the experimental results.

Since the simulations were able to simulate the experiments within reasonable accuracy, the simulations have been extended for ERA sandwich inclined at $45^{\circ}$ using the same simulation setup, and the results show that the penetration is further reduced as the inclination angle of the ERA sandwich is increased.

Following conclusions can be drawn from the study presented in this paper:

(1) The cover plate contributes towards the reduction in the penetration of the EFP as it reduces the residual length of the EFP and also deforms the nose shape of the EFP.

(2) The reduction in length of the EFP and nose deformation caused by the cover plate does not affect the initiation of the ERA in the configurations tested. Despite the reduction in residual length of the EFP, it still possesses sufficient energy to initiate the explosive in the ERA sandwich. 


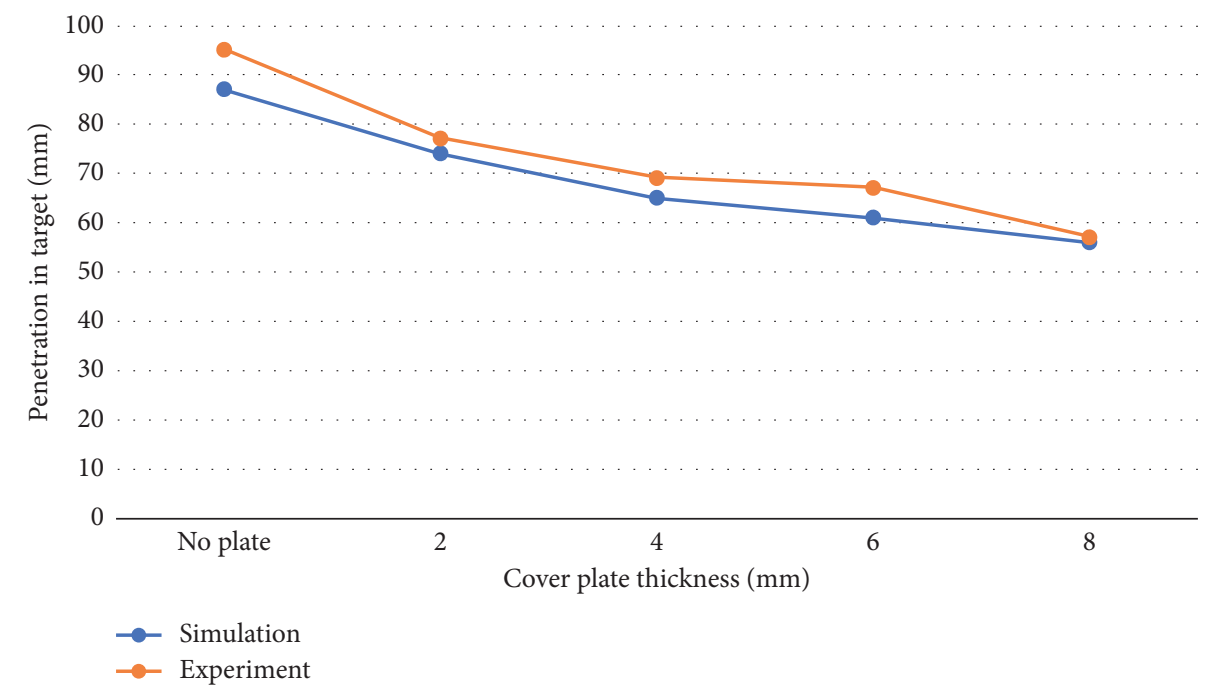

FIGURE 11: Experimental and simulated residual penetration in target.
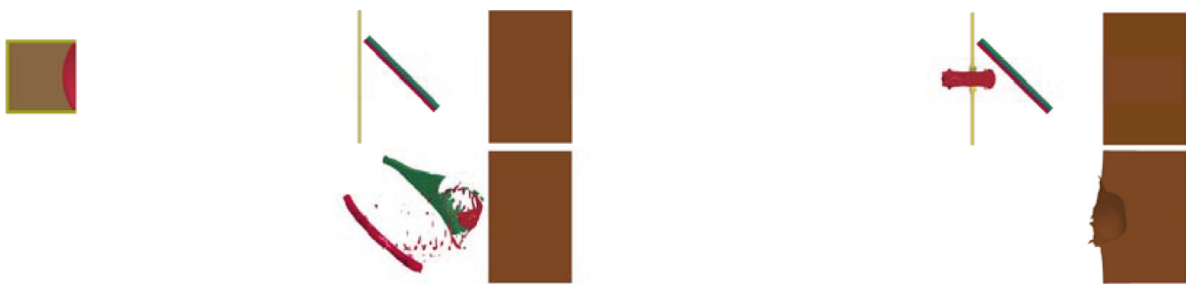

Figure 12: Simulation of EFP against $4 \mathrm{~mm}$ cover plate, ERA at $45^{\circ}$ at $0,226,320$, and $450 \mu$ s.
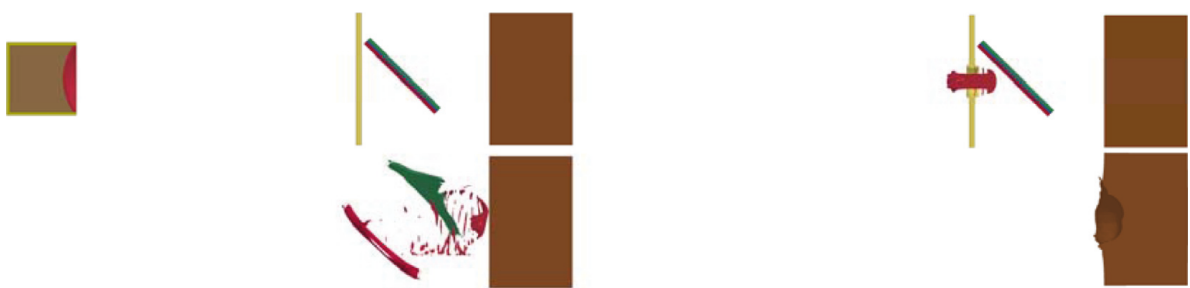

Figure 13: Simulation of EFP against $8 \mathrm{~mm}$ cover plate, ERA at $45^{\circ}$ at $0,225,329$, and $450 \mu$ s.

TABLe 3: Comparison of EFP residual penetration after cover and ERA interaction.

\begin{tabular}{|c|c|c|c|c|c|c|}
\hline \multirow[b]{2}{*}{$\begin{array}{l}\text { ERA cover } \\
\text { thickness }(\mathrm{mm})\end{array}$} & \multicolumn{3}{|c|}{ ERA inclined at $30^{\circ}$} & \multicolumn{3}{|c|}{ ERA inclined at $45^{\circ}$} \\
\hline & $\begin{array}{l}\text { EFP residual } \\
\text { length } \\
\text { after cover } \\
\text { plate }(\mathrm{mm})\end{array}$ & $\begin{array}{l}\text { EFP residual } \\
\text { length after } \\
\text { ERA }(\mathrm{mm})\end{array}$ & $\begin{array}{l}\text { Simulated } \\
\text { penetration } \\
\quad(\mathrm{mm})\end{array}$ & $\begin{array}{l}\text { EFP residual length after } \\
\text { cover plate }(\mathrm{mm})\end{array}$ & $\begin{array}{l}\text { EFP residual length } \\
\text { after ERA (mm) }\end{array}$ & $\begin{array}{c}\text { Simulated } \\
\text { penetration }(\mathrm{mm})\end{array}$ \\
\hline 4 & 81 & 44 & 65 & 81 & 36 & 45 \\
\hline 8 & 73 & 39 & 56 & 73 & 30 & 37 \\
\hline
\end{tabular}

(3) The reduction in penetration is directly proportional to the thickness of the cover plate, which is mainly caused due to reduction in overall length of the EFP after interaction with the cover plate.
(4) Also the study shows that the penetration is inversely proportional to the inclination angle of the ERA sandwich. Increasing the inclination angle decreases the penetration in the target. 
(5) The formation, interaction, penetration, and initiation of the EFP with the plate, ERA, and target can be simulated using numerical simulation within reasonable accuracy.

(6) The simulations have been able to predict the penetration to within $10 \%$ of the experimental results.

\section{Data Availability}

The data used to support the findings of this study are available from the corresponding author upon request.

\section{Conflicts of Interest}

The authors declare that they have no conflicts of interest.

\section{References}

[1] M. Held, "Protective arrangement against projectiles, particularly hollow explosive charge projectiles," Patent US4368660A, 1983.

[2] E. Lidén, J. Lundgren, and M. Bergh, "EFP warheads against explosive reactive armour," in Proceedings of the 28th International Symposium on Ballistics, Atlanta, GA, USA, September 2014.

[3] M. Held, "Comparison of explosive reactive armour against different threat levels," Propellants, Explosives, Pyrotechnics, vol. 24, no. 2, pp. 76-77, 1999.

[4] M. F. Rasheed, W. Cheng, A. Raza, and S. M. Zakir, "Analysis of EFP and single sandwich ERA interaction," in Proceedings of the 13th International Bhurban Conference on Applied Sciences and Technology (IBCAST), pp. 1-6, Islamabad, Pakistan, January 2016.

[5] W. Jian, C. Hong-gen, and Z. Jian-long, "EFP penetrating explosive reactive armor," Journal of Nanjing University of Science and Technology (Natural Science), vol. 32, no. 1, pp. 9-12, 2008.

[6] K. Weimann, "Research and development in the area of explosively formed projectiles charge technology," Propellants, Explosives, Pyrotechnics, vol. 18, no. 5, pp. 294-298, 1993.

[7] J. O. Hallquist, LS-DYNA Theory Manual. 7374 Las Positas Road, Livermore Software Technology Corporation, Livermore, CA, USA, 2006.

[8] D. J. Steinberg, S. G. Cochran, and M. W. Guinan, "A constitutive model for metals applicable at high-strain rate," Journal of Applied Physics, vol. 51, no. 3, pp. 1498-1504, 1980.

[9] J. W. Kury et al., "Metal acceleration by chemical explosives," in Proceedings of the 4th International Symposium on Detonation, U.S. Naval Ordnance Laboratory, White Oak, MD, USA, October 1965.

[10] E. L. Lee and C. M. Tarver, "Phenomenological model of shock initiation in heterogeneous explosives," Physics of Fluids, vol. 23, no. 12, pp. 2362-2372, 1980.

[11] P. A. Urtiew, K. S. Vandersall, C. M. Tarver, F. Garcia, and J. W. Forbes, "Shock initiation experiments and modeling of composition B and C-4," in Proceedings of the 13th International Detonation Symposium, Norfolk, VA, USA, June 2006. 


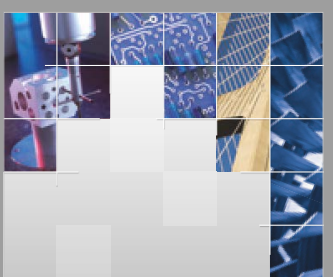

\section{Enfincering}
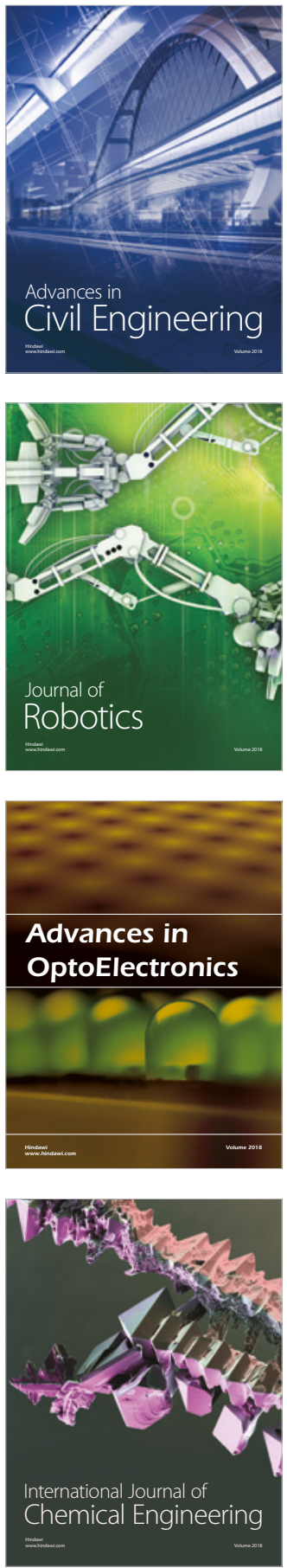

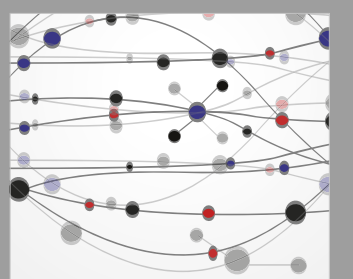

\section{Rotating \\ Machinery}

The Scientific World Journal

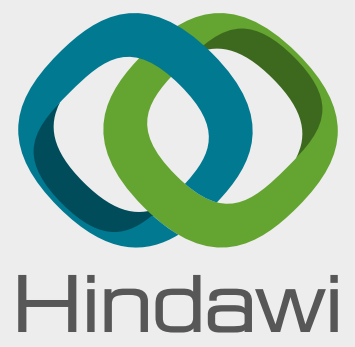

Submit your manuscripts at

www.hindawi.com
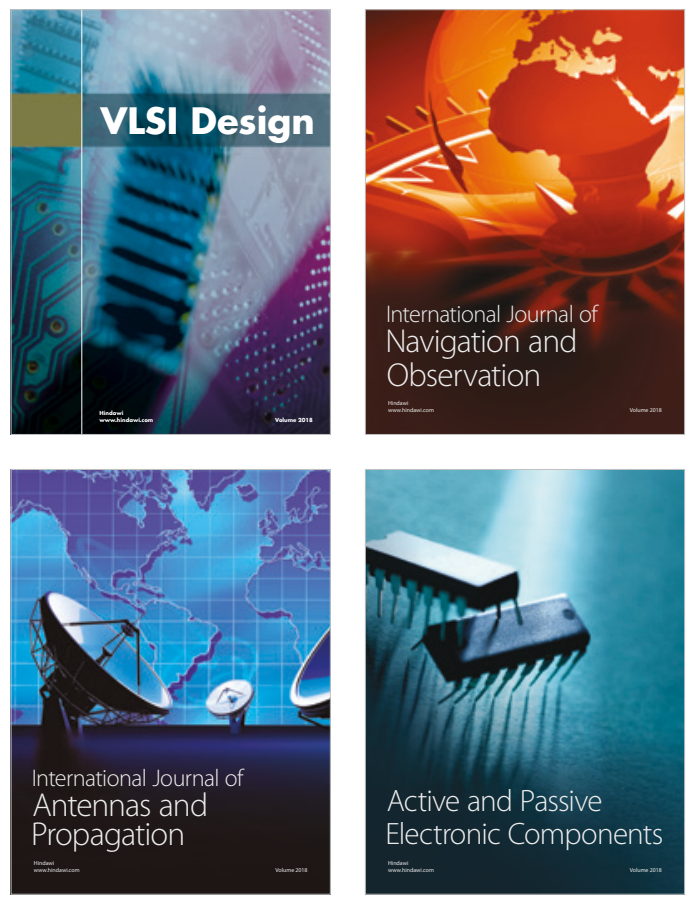
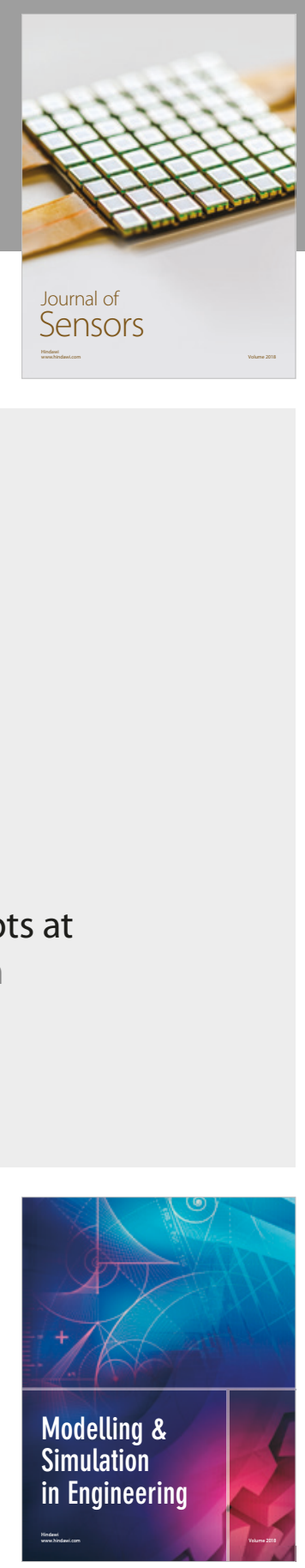

\section{Advances \\ Multimedia}
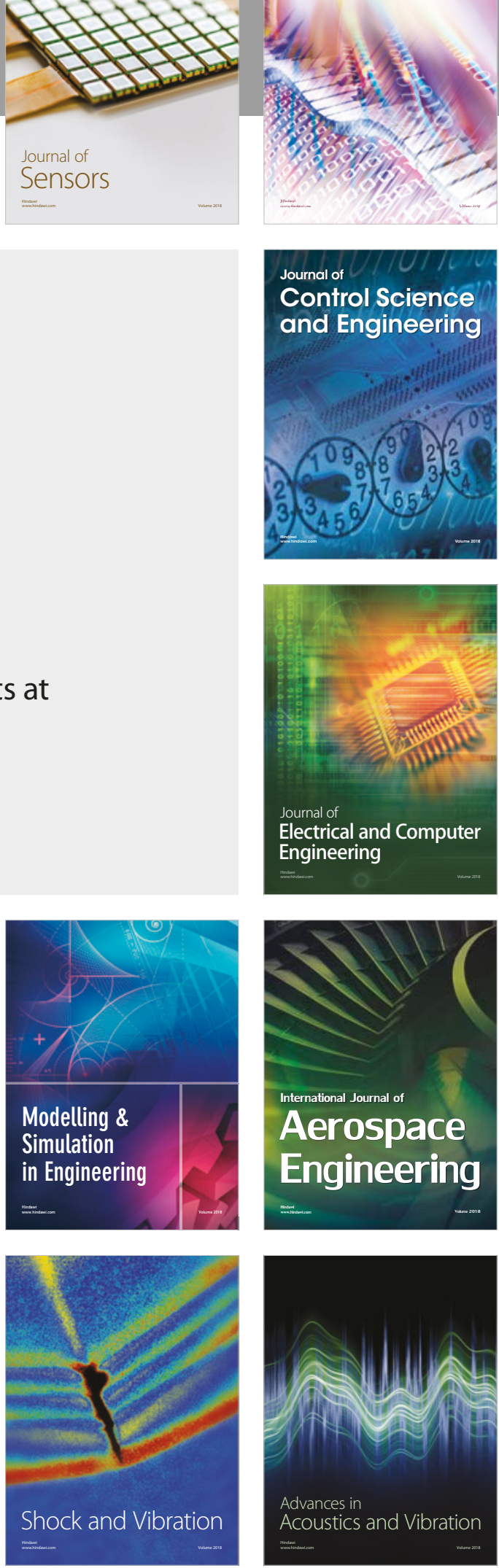